\title{
Observações em um ninho de sovi Ictinia plumbea (Gmelin, 1788) (Falconiformes: Accipitridae) no sul do Brasil
}

\author{
Fábio André Facco Jacomassa \\ Laboratório de Ornitologia e Animais Marinhos, Bloco D, Centro 2 \\ Universidade do Vale do Rio dos Sinos \\ Avenida Unisinos, 950 - B, CEP 93.022-000, São Leopoldo - RS, Brasil \\ Autor para correspondência \\ fabioafj@gmail.com
}

Submetido em 26/04/2010

Aceito para publicação em 04/10/2010

\section{Resumo}

Entre agosto e dezembro de 2005 e setembro e dezembro de 2006 foram despendidas 80 h de observações em um ninho de sovi (Ictinia plumbea), localizado na borda de um fragmento no município de Frederico Westphalen, RS, Brasil. Neste período foram obtidos dados sobre o comportamento de cópula, cuidado parental, manutenção do ninho e alimentação. Em agosto de 2005 e início de outubro de 2006, foram observadas cópulas que duraram em média $9,5 \mathrm{~s}$. Os pais se revezavam na incubação. No início de novembro foi constatada a presença de ninhegos (um em cada estação reprodutiva), e nessa época os pais alimentavam os filhotes com insetos pequenos (Hymenoptera e Coleoptera) e faziam a manutenção do ninho. Os filhotes ao tornarem-se jovens eram alimentados com insetos maiores (Odonata, Lepidoptera - Myelobia smerintha e Orthoptera - Tropidacris collaris). Os pais inibiam a aproximação de possíveis predadores. Eles, além dos itens alimentares que forneciam aos filhotes, consumiram frutos de batinga Eugenia rostrifolia e a carcaça de um Piaya cayana. O período de incubação observado no presente estudo concorda com aquele já descrito na literatura para outras regiões. Por fim, os dados obtidos permitem inferir sobre a época reprodutiva da espécie no Sul do Brasil e ainda ampliam o conhecimento sobre sua dieta para frutos e carcaças de animais.

Palavras-chave: Dieta, Nidificação, Rio Grande do Sul

\section{Abstract}

Observations of a nest of the Plumbeous Kite, Ictinia plumbea (Gmelin, 1788) (Falconiformes: Accipitridae) in southern Brazil. Between August and December 2005 and September and December 2006, $80 \mathrm{~h}$ of observations were observed on a nest of Plumbeous Kite (Ictinia plumbea), located on the edge of a fragment in the town of Frederico Westphalen, RS, Brazil. During this period data were obtained on the behavior of copulation, parental care, nest maintenance and feeding. In early August 2005 and October 2006, copulations were observed that lasted on average $9.5 \mathrm{~s}$. The parents took turns incubating. In early November, the presence of nestlings was confirmed (one in each breeding season), and this time the parents fed the chicks with small insects (Hymenoptera and Coleoptera) and carried out the maintenance of the nest. The nestlings that were developing into young birds were fed with larger insects (Odonata, Lepidoptera - Myelobia smerintha and Orthoptera - Tropidacris collaris). The parents inhibited the approach of potential predators. Besides the food items supplied to the pups, they consumed fruits of Batinga Eugenia rostrifolia and a Piaya cayana carcass. The incubation period observed in this study agrees with that period already described in the literature for other regions. Finally, the data obtained allow inference of the reproductive season of this species in southern Brazil and also expand the knowledge about their diet to fruits and animal carcasses.

Key words: Diet, Nesting, Rio Grande do Sul 


\section{Introdução}

O sovi (Ictinia plumbea) é um Falconiforme comum e de ampla distribuição, que ocorre desde o leste do México até a Bolívia, a leste dos Andes, Paraguai, norte da Argentina, e em praticamente todo o Brasil (THIOLLAY, 1994; SICK, 1997; FERGUSONLEES; CHRISTIE, 2001). Está presente o ano todo no Suriname sendo migratório nos limites Norte e Sul de sua distribuição, onde muitas das suas populações do México e América Central passam o inverno na América do Sul (BROWN; AMADON, 1968). O limite Sul de sua distribuição é a metade Norte (2830"S) do Rio Grande do Sul, a Sul do sopé da escarpa de Santa Maria até Torres, não sendo registrado nas regiões mais altas do Nordeste deste estado (BELTON, 1984). No Rio Grande do Sul a espécie é residente de verão, tendo seu registro mais cedo em 15 de setembro, e mais tarde em 7 de março (final do inverno, primavera até o final do verão) (BELTON, 1984). Ocorre com frequência nas matas, bordas de florestas, florestas secundárias, áreas abertas e em matas de galeria (BELTON, 1984; THIOLLAY, 1994; SICK, 1997; FERGUSON-LEES; CHRISTIE, 2001).

Sua alimentação é composta principalmente de insetos, apanhados com os pés em pleno vôo ou voando de boca aberta atrás de pequenos enxames de cupins, estes são ingeridos em pleno ar (HAVERSCHIMIDT, 1962; THIOLLAY, 1994; SICK, 1997; FERGUSON-LEES; CHRISTIE, 2001). Alimentam-se ainda de pequenos lagartos e anuros arborícolas, serpentes, aves e raramente de caracóis (THIOLLAY, 1994; SEAVY et al., 1997; FERGUSON-LEES; CHRISTIE, 2001). Além disso, procuram queimadas onde apanham insetos e pequenos répteis no solo, eventualmente também capturam aves feridas (BELTON, 1984; SICK, 1997, FERGUSONLEES; CHRISTIE, 2001). Também durante emergência em massa de cigarras gigantes nos períodos chuvosos podem passar horas por dia acompanhando de perto grupos de saguis Calitrix para capturar as cigarras que eles levantam (FERGUSON-LEES; CHRISTIE, 2001). Seavy et al. (1997), na Guatemala, registraram sua dieta como sendo composta por $92,5 \%$ de insetos, $6 \%$ de lagartos, $1,1 \%$ de serpentes, $0,3 \%$ de aves, $0,2 \%$ de morcegos, e somente $0,1 \%$ de anuros.
Poucos trabalhos versam sobre seu comportamento reprodutivo (SKUTCH, 1947; BELTON, 1984; SEAVY et al., 1998; LOURDES-RIBEIRO et al., 2003). Brown e Amadon (1968) citam a sua época reprodutiva em março e abril no Suriname, e em outubro e novembro na Província de Misiones na Argentina. Belton (1984) observou em 26/11/1974 onde é hoje o Parque Estadual do Espigão Alto em Barração, Rio Grande do Sul, dois adultos alimentando com insetos grandes um número indeterminado de filhotes, comenta que os filhotes estavam em um ninho aparentemente frágil, entre 10 a $12 \mathrm{~m}$ do solo.

Este trabalho é um estudo de caso que relata o comportamento reprodutivo e a dieta de I. plumbea, obtidos em 80h de observações entre agosto de 2005 e dezembro de 2006, com base em um ninho situado na borda de um fragmento de mata secundária $\left(27^{\circ} 21^{\prime} 37^{\prime \prime} \mathrm{S}\right.$ e 53⒉'37'W) (Floresta Estacional Decidual) de 47ha, localizado no município de Frederico Westphalen, RS.

\section{Material e Métodos}

As observações foram realizadas com auxílio de binóculos $10-30 \times 25 \mathrm{~mm}$ e a vista desarmada, distante aproximadamente $15 \mathrm{~m}$ da árvore que continha o ninho. Em 2005 foram 3h de observações em agosto, 27h em novembro, e 30h em dezembro, em 2006 foram $6 \mathrm{~h}$ em outubro, $7 \mathrm{~h}$ em novembro, e $7 \mathrm{~h}$ em dezembro, totalizando assim $80 \mathrm{~h}$ de observações. As fotografias foram feitas com uma câmera compacta com lente 28$300 \mathrm{~mm}$. Restos de alimentos foram procurados sob o ninho e poleiros próximos.

\section{Resultados e Discussão}

Nos dias 10/08/2005 e 22/08/2005 foram registradas duas cópulas de I. plumbea na área em questão, ambas com duração de 10 segundos. Em 02/11/2005 foi encontrado um ninho raso, construído de gravetos secos, bem como de gravetos verdes contendo folhas. $\mathrm{O}$ mesmo possuía o formato de tigela, com 52 centímetros de diâmetro e estava a $8 \mathrm{~m}$ do solo, situado no galho de uma batinga (Eugenia rostrifolia D. Legrand.), que apresentava $12 \mathrm{~m}$ de altura. Nesse mesmo dia a 
manutenção do ninho era feita ao longo do dia pelos pais usando galhos verdes. Os pais revezavam-se na incubação (Figura 1a).

Em 09/11/2005, um ninhego com a plumagem toda branca do corpo com aproximadamente três semanas de idade foi visto no interior do ninho. Este era alimentado com insetos pequenos (até $10 \mathrm{~mm}$ de comprimento Hymenoptera e Coleoptera). Os pais se revezavam ao lado do ninho, na busca por alimento e nos cuidados parentais durante todo o dia (Figura 1b).

No dia 22/11/2005, os pais já deixavam o ninhego sozinho no ninho. No dia 27/11/2005, já com capuz cinza e as pontas das asas e costas mais escurecidas, o ninhego com pouco menos de seis semanas saiu do ninho e ficou efetuando movimentos contínuos com as asas, fase característica da aprendizagem de vôo (veja LOURDES-RIBEIRO et al., 2003). No dia 11/12/2005 o filhote apresentava características de um juvenil: costas e ventre escuros e o peito com um tom amarelado estriado (Figura 1c). Nesta etapa eram oferecidos ao filhote insetos maiores (acima de $15 \mathrm{~mm}$ de comprimento -
Odonata, Lepidoptera e Orthoptera). No dia 13/12/2005, o jovem saiu do ninho e empoleirou em um galho ao lado (cerca de $1 \mathrm{~m}$ distante dele). Em 15/12/2005 o jovem voou para árvores próximas do ninho.

O ninho acompanhado em 2005 foi reutilizado pela espécie em 2006. Em 01/10/2006 foram registradas duas cópulas, com duração de 8 e 10 segundos, respectivamente. No dia 14/11/2006 um ninhego muito pequeno com aproximadamente duas semanas foi avistado no interior do ninho. Em 02/12/2006, o filhote foi observado fora dele fazendo manutenção no mesmo com galhos verdes trazidos pelos pais. No dia 08/12/2006 o, agora jovem (plumagem de juvenil) batia as asas perto do ninho e arrumava constantemente suas penas; e no dia 15/12/2006, ele já voava aos arredores do ninho.

Diversas vezes durante períodos de chuva fraca os adultos permaneciam nas proximidades do ninho, e quando a chuva se tornava mais forte eles ficavam ao lado do ninho junto ao filhote. Após o dia 15 de dezembro, nenhum dos dois filhotes acompanhados, bem como os pais, foram mais avistados nas cercanias.
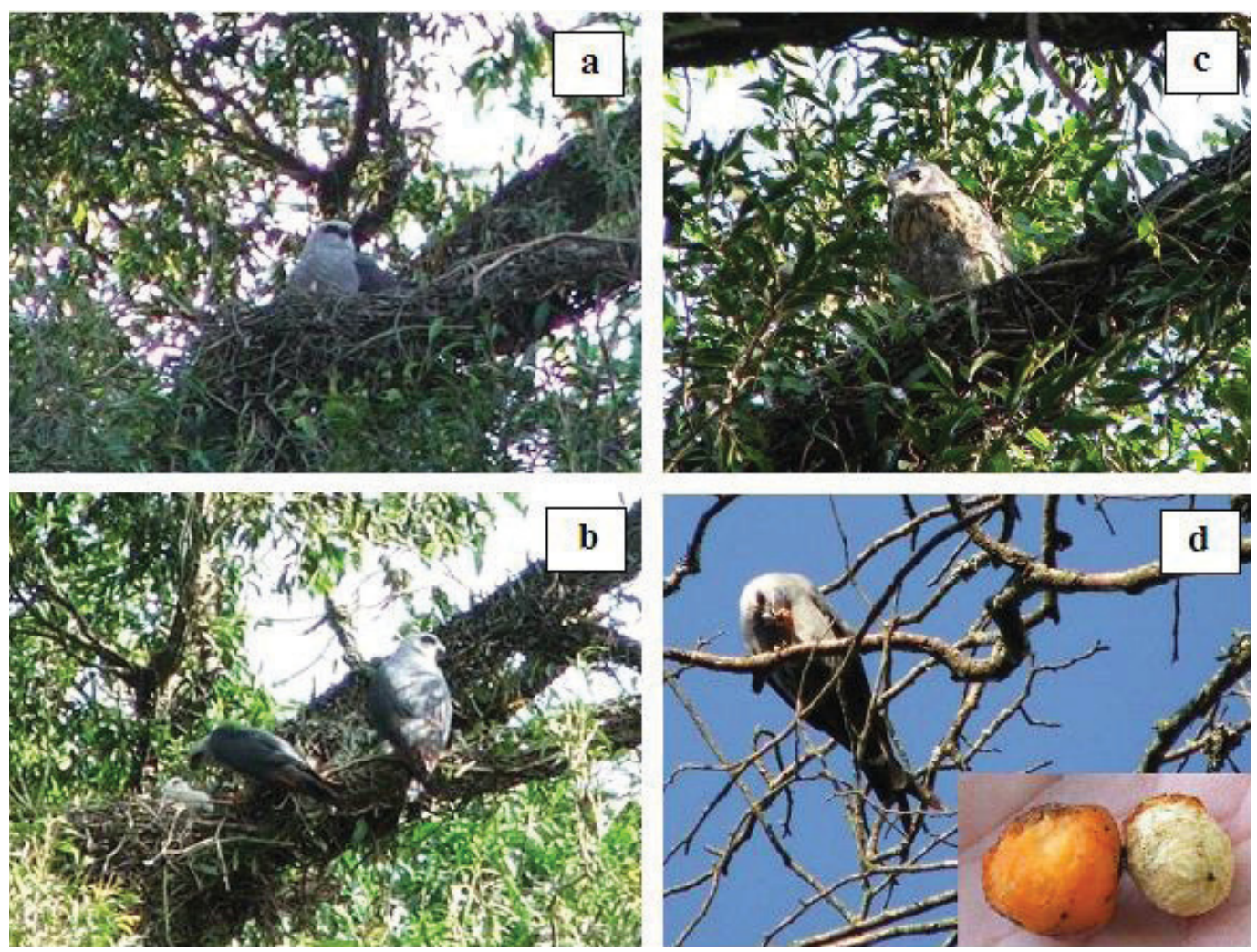

FIGURA 1: Adulto no ninho chocando (a), adulto alimentando o ninhego (b), jovem fora do ninho (c), e adulto alimentando-se da polpa de frutos de batinga (d). 
Os registros obtidos nas duas estações reprodutivas sugerem um período de incubação de cerca de 30 dias, visto que foram registradas cópulas dia 01/10/2006 e no dia 14/11/2006 um ninhego com cerca de duas semanas foi avistado no ninho. Seavy et al. (1998), na Guatemala de 1991 a 1996, observaram de 32 a 33 dias de incubação. O revezamento dos adultos na incubação também foi verificado por esses autores, observando 6 ninhos entre 1994 e 1995 registraram que os adultos se revezavam na incubação permanecendo em média 97,8\% do tempo incubando os ovos, também que em média uma das aves permanecia $61,5 \%$ desse tempo e a outra $38,8 \%$, esses dados não foram quantificados neste trabalho. Em nenhum momento, até sua partida dos arredores do ninho no final de dezembro os dois jovens, com pouco mais de dois meses de idade, buscaram alimento. Eles foram alimentados exclusivamente pelos pais. Skutch (1947) no início de setembro de 1939 observando um ninho de sovi no sopé dos Andes no Equador registrou um filhote batendo as asas no ninho, este também era alimentado exclusivamente pelos pais.

Os registros feitos nesse trabalho e a literatura consultada (BELTON, 1984; LOURDES-RIBEIRO et al., 2003) apontam de agosto a dezembro como sendo sua época reprodutiva (cópulas até o abandono do ninho e imediações pelo filhote) no Sul do continente Americano, visto que Belton (1984) registrou filhotes no Rio Grande do Sul no final de novembro, e Lourdes-Ribeiro et al. (2003), em trabalho realizado no Paraná, citam de setembro a dezembro como sua época reprodutiva. Seavy et al. (1998) registraram sua época reprodutiva na Guatemala (América Central) do final de fevereiro até o início de junho, e Skutch (1947) no Equador observou um filhote do final de agosto a setembro.

Durante as observações os adultos foram "atacados" (mobbing behavior - ALTMANN, 1956) por Accipiter striatus e Myiodynastes maculatus, e apresentaram comportamento agressivo contra Guira guira, Caracara plancus, Ramphastos dicolurus e Cyanocorax chrysops. Estas quatro espécies de aves, G. guira, C. plancus, $R$. dicolorus e $C$. chrysops são conhecidas por predar filhotes de outras aves (ver MACEDO, 1994; SICK, 1997), o que pode explicar tal comportamento.

Os adultos alimentaram os filhotes com formigas e vespas (Hymenoptera), besouros (Coleoptera), libélulas
(Odonata), mariposas (Lepidoptera-Myelobia smerintha Hübner, 1821) e gafanhotos (Orthoptera - Tropidacris collaris (STOLL, 1813). Os adultos ingeriram os mesmos itens que forneceram aos filhotes. Também consumiram uma carcaça de ave - dia 23/08/2006 um adulto foi avistado carregando e ingerindo um Piaya cayana (Linnaeus, 1766) - e a polpa de frutos de batinga (E. rostrifolia, Myrtaceae). Os frutos eram apanhados da própria árvore em que tinham o ninho e a polpa consumida enquanto estavam empoleirados em árvores próximas (Figura 1d).

Houve uma explosão populacional de mariposas de bichos-da-taquara ( $M$. smerintha) de setembro a outubro de 2006 e os adultos alimentaram-se com muita frequência destas. Sazima (2009) em um parque urbano, em Campinas, SP, observou I. plumbea apresando cigarras gigantes que emergiam em grande número, o autor comenta que o sovi no período estava em época reprodutiva (setembro a meados de novembro de 2007), e nessas ocasiões pode se especializar na predação de cigarras, o mesmo pode ter ocorrido neste trabalho, embora também possa ter sido oportunista devido à abundância e facilidade de capturá-las. A literatura cita o consumo de insetos em explosões populacionais por Accipitrídeos (e.g. Leptodon cayanensis, Accipiter badius, Pernis ptilorhyncus) e outras aves (EISENMANN, 1961; HIMMATSINHJI, 1985; FERGUSON-LEES; CHRISTIE, 2001; GUSSONI; CAMPOS, 2003; OLSON; ALVARENJA, 2006).

A literatura(SCHUTCH, 1947; HAVERSCHIMIDT, 1962; BROWN; AMADON, 1968; BELTON, 1984; THIOLLAY, 1994; SICK, 1997; SEAVY et al., 1997; FERGUSON-LEES; CHRISTIE, 2001; LOURDESRIBEIRO et al., 2003) não relata o consumo de animais mortos (carniça) por I. plumbea, embora algumas espécies de Accipitrídeos (e.g. Buteogallus urubitinga, Geranoaetus, Harpyhaliaetus coronatus, Oroaetus isidori, Caracara plancus) comam ocasionalmente carniça (SICK, 1997; GRANZINOLLI et al., 2006; FERGUSON-LEES; CHRISTIE, 2001).

Algumas espécies de aves de rapina, como Falco tinnunculus (NOGALES et al., 2002), Elanus leucurus, Heterospizias meridionalis, Rupornis magnirostris (HAVERSCHIMIDT, 1962) e Bubo virginianus 
(PEARSON; ORTEGA, 2001) são potenciais dispersoras secundárias das sementes consumidas por suas presas. O consumo de frutos por parte das aves de rapina não é comum, na literatura alguns poucos trabalhos (GALETTI; GUIMARÃES JR., 2004; OLMOS et al., 2006) versam sobre isso, embora haja evidências que alguns Accipitrídeos consumam ativamente frutos pequenos e sementes com arilo carnudo (GALETTI; GUIMARÃES JR., 2004). Caracara plancus consome acuri (Attalea phalerata, Arecaceae) e dendê (Elaeis guineensis, Arecaceae) (GALETTI; GUIMARÃES JR., 2004; SICK, 1997). Espécies dos gêneros Milvago e Daptrius também comem frutos, Cathartes aura consome frutos de palmeiras como os cocos da macaúba (Acrocomia sclerocarpa, Arecaceae) e dendê (E. guinnensis), ainda, Elanoides e Buteogallus urubitinga consomem ocasionalmente frutos (SICK, 1997). Olmos et al. (2006) observaram Elanoides forficatus apanhando dendês caídos no solo, e os consumindo durante o vôo. Estes autores registraram um Milvago chimachima pousado sobre os cachos do dendê alimentando-se da sua polpa, e também outro $M$. chimachima pousado no chão comendo a polpa do fruto de um pequi (Caryocar brasiliensis, Caryocaraceae).

Os dados aqui apresentados ampliam o conhecimento sobre a reprodução e dieta de I. plumbea, trazendo o tempo da cópula e apontando sua época reprodutiva no Sul do Brasil, bem como abrange o conhecimento sobre sua dieta para carcaças de animais e frutos.

\section{Agradecimentos}

O autor agradece a Marco Aurélio Pizo e a Marcelo Fischer Barcellos dos Santos pela leitura e sugestões ao manuscrito original, aos revisores pelas valiosas sugestões, a Glayson Ariel Bencke, Carla Suertegaray Fontana e Felipe Zílio pela ajuda com bibliografias, e também à Cátia e Anelise da Quorum Eventos e Língua Estrangeira pela revisão do abstract.

\section{Referências}

ALTMANN, S. A. Avian mobbing behavior and predator recognition. The Condor, Albuquerque, v. 58, n. 4, p. 241-253, 1956.
BELTON, W. Birds of Rio Grande do Sul, Brazil. Part 1, Rheidae through Furnariidae. Bulletin of the AMNH, New York, v. 178, p. 369-636, 1984.

BROWN, L.; AMADON, D. Eagles, hanks and falcons of the world. 2 vols. New York: McGraw-Hill, 1968. 945 p.

EISENMANN, E. Favorite foods of neotropical birds: flying termites and Cecropia catkins. The Auk, Albuquerque, v. 78, p. 636-638, 1961.

FERGUSON-LEES, J.; CHRISTIE, D. A. Raptors of the World. New York: Houghton Mifflin Company, 2001. 992 p.

GALETTI, M.; GUIMARÃES JR., P. R. Seed dispersal of Attalea phalerata (Palmae) by Crested caracaras (Caracara plancus) in the Pantanal and a review of frugivory by raptors. Ararajuba, Londrina, v. 12, n. 2, p. 133-135, 2004.

GRANZINOLLI, M. A. M.; PEREIRA, R. J. G.; MOTTAJUNIOR, J. C. The crowned solitary-eagle Harpyaliaetus coronatus (Accipitridae) in the cerrado of Estação Ecológica de Itirapina, southeast Brazil. Revista Brasileira de Ornitologia, São Leopoldo, v. 14. n. 4, p. 429-432, 2006.

GUSSONI, C. O. A.; CAMPOS, R. P. Registro de uma grande concentração de aves se alimentando de "aleluias" (Isoptera). Lundiana, Belo Horizonte, v. 4, n. 1, p. 71, 2003.

HAVERSCHIMIDT, E. Notes on the feeding habits and food of some hawks in Surinam. The Condor, Albuquerque, v. 64, n. 2, p. 154-158, 1962.

HIMMATSINHJI, M. K. Peculiar felding behaviour of the shikra Accipiter badius (Gmelin) and the honey buzzard Pernis ptilorhyncus (Temminck). Journal Bombay Natural History Society, Mumbai, v. 83, p. 201-202, 1985.

LOURDES-RIBEIRO, A.; GIMENES, M. R.; ANJOS, L. Observações sobre o comportamento reprodutivo de Ictinia plumbea (Falconiformes: Accipitridae) no Campus da Universidade Estadual de Maringá, Paraná, Brasil. Ararajuba Londrina, v. 11, n. 1, p. 85-87, 2003.

MACEDO, R. H. Inequities in parental effort and costs of communal breeding in the Guira Cuckoo. Ornitologia Neotropical, Ciudad de Mexico, v. 5, n. 2, p. 79-90, 1994.

NOGALES, M.; QUILIS, V.; MEDINA, F. M.; MORA, J. L.; TRIGO, L. S. Are predatory birds effective secondary seed dispersers? Biological Journal of the Linnean Society, London, v. 75, p. 345-352, 2002.

OLSON, S. L.; ALVARENGA, H. M. F. An extraordinary feeding assemblage of birds at a termite swarm in the Serra da Mantiqueira, São Paulo, Brasil. Revista Brasileira de Ornitologia, São Leopoldo, v. 14, n. 3, p. 297-299, 2006.

OLMOS, F.; PACHECO, J. F.; SILVEIRA, L. F. Notas sobre aves de rapina (Cathartidae, Acciptridae e Falconidae) brasileiras. Revista Brasileira de Ornitologia, São Leopoldo, v. 14, n. 4, p. 401-404. 2006.

PEARSON, D. E.; ORTEGA, Y. K. Evidence of an indirect dispersal pathway for Spotted Knapweed, Centaurea maculosa, seeds, via Deer Mice, Peromyscus maniculatus, and Great Horned Owls, Bubo virginianus. Canadian Field Naturalist, Ottawa, v. 115, p. 354-354, 2001.

SAZIMA, I. Insect cornucopia: various bird types prey on the season's first giant cicadas in an urban park in southeastern Brazil. Biota Neotropica, Campinas, v. 9, n. 1, p. 259-262, 2009. 
SEAVY, N. E.; SCHULZE, M. D.; WHITACRE, D. F.; VASQUEZ, M. A. Diet and hunting behavior of the Plumbeous Kite. Wilson Bulletin, Albuquerque, v. 109, n. 3, p. 526-532, 1997.

SEAVY, N.E.; SCHULZE, M.D.; WHITACRE, D.F.; VASQUEZ, M. A. Breeding biology and behavior of the plumbeous kite. Wilson Bulletin, Albuquerque, v. 110, n. 1, p. 77-85, 1998.

SHANAHAN M.; SAMSOM, S. O.; COMPTON S. G.; CORLETT R. Fig-eating by vertebrate frugivores: a global review. Biological Reviews, Cambridge, v. 76, p. 529-572, 2001.
SICK, H. Ornitologia brasileira. Rio de Janeiro: Nova Fronteira, 1997. $862 \mathrm{p}$.

SKUTCH, A. F. A nesting of the plumbeous kite in Ecuadors. The Condor, Albuquerque, v. 49, n. 1, p. 25-31, 1947.

THIOLLAY, J. M. Family Accipitridae (hawks and eagles). In: DEL HOYO, J.; ELLIOT, A.; SARGATAL, J. (Ed.). Handbook of the birds of the world, New World vultures to guineafowl. Barcelona: Lynx Edicions, 1994. p. 52-205. 